\title{
Exposure to particulate air pollution at different living locations and respiratory symptoms - an application of satellite information
}

\author{
Hak-Kan Lai, Sai-Yin Ho, "Chit-Ming Wong, Kwok-Kei Mak, Wing-Sze Lo, Tai-Hing Lam \\ School of Public Health, The University of Hong Kong, China \\ *correspondence: \\ Address: 5/F William MW Mong Block, Faculty of Medicine Building, 21 Sassoon Road; Phone: (+852) 2819 9280; \\ Fax: (+852) 28559528; Email: hrmrwcm@hkucc.hku.hk
}

Funding: This work was supported by the University Research Committee, Strategic Research Theme on Public Health, The University of Hong Kong.

\begin{abstract}
Objective: To estimate respiratory ill-health effects of particulate air pollutant exposures measured at different aggregated geographical locations of individual residential addresses based on satellite information.

Method: We assessed the presence of respiratory symptoms of having frequent cough or sputum among school students 11 to 20 years old $(n=9,881)$. Daily particulate air pollution levels at students' living locations were derived from the surface extinction coefficients measured by the satellite and the measurements from the air pollutant monitoring stations at ground level.

Results: Adjusted odds ratio (OR) [95\% C.I.] of having respiratory symptoms was $1.047[1.005,1.091]$ per $10 \mu \mathrm{g} \mathrm{m}{ }^{-3}$ increase in $\mathrm{PM}_{10}$ concentration. Specificity tests showed that adjusted OR of having other symptoms were not significant $(\mathrm{P}=0.20$ to 0.94$)$.

Conclusion: Exposures to $\mathrm{PM}_{10}$ at different geographical locations were associated with increased odds of having respiratory symptoms (cough or sputum) but not with other symptoms unrelated to air pollution.

\section{THIS PAPER WAS PUBLISHED IN INTERNATIONAL JOURNAL OF ENVIRONMENTAL HEALTH RESEARCH IN 2010.}

Lai HK, Ho SY, Wong CM, Mak KK, Lo WS, Lam TH. Exposure to particulate air pollution at different living locations and respiratory symptoms - an application of satellite information. International Journal of Environmental Health Research. 2010;20:219-230.

\section{Introduction}

Cough and sputum are common problems in school students, and are usually associated with viral infection (Monto et al 1971). But they are also found to be associated with air pollution (Goren et al 1990; Schwartz et al 1991; Ong et al 1991; Pope and Dockery 1992; Schwartz et al 1994; Peters et al 1996; BraunFahrlander et al 1997; Milligan et al 1998; Qian et al 2000; Bayer-Oglesby et al 2005). The associations are stronger with coarse particulates than with fine particulates and gaseous air pollutants (Zhang et al 2002). Epidemiological studies for the health effects of particulate air pollutant usually based the exposure measurement on ambient air quality monitoring stations. These stations usually scatter scarcely around large geographical areas, so that the measurements should not be representative of the exposure at individual locations that are far away from the stations. This limitation, however, can be overcome by using the satellite imaging data that are routinely captured over a defined geographical area.

Recently, the National Aeronautics and Space Administration (NASA) satellite data derived from Moderateresolution Imaging Spectroradiometer (MODIS) (Chu et al 2003; Wang and Christopher 2003) have been shown to be good measures for air pollution, especially for particulate pollutants which could be estimated in any geographical points of the globe (Gupta et al 2006). With control for cloudiness and humidity, monthly average of PM $_{10}$ levels in all geographical points with $1-\mathrm{km}^{2}$ resolution over the territory of Hong Kong have been estimated (Li et al 2005), based on aerosol optical depth using validated algorithms and aerosol models (Kaufman et al 1997; Chu et al 2002; Remer et al 2005). MODIS is useful for resolution up to about $10 \mathrm{~km}^{2}$ rather than $1 \mathrm{~km}^{2}$; but this method is highly uncertain (Veefkind et al 2007) as has been reported in a formal evaluation of the remote sensing approach in comparison with the regulatory network of monitoring measurement in Hong Kong ( $\mathrm{Li}$ et al 2005).

In the present study, we applied the satellite-detected information to derive daily $\mathrm{PM}_{10}$ levels at different geographical locations and to study whether exposures to particulate air pollution at individuals' residential and schooling locations is associated with respiratory symptoms in secondary school students in Hong Kong.
\end{abstract}




\section{Methods \\ Subjects}

The health data were collected from a cross-sectional study of the Hong Kong Student Obesity Surveillance (HKSOS) on secondary school Chinese adolescents aged 11 to 20 years (i.e. students from Form 1 to 7, equivalent to Grade 7-12 in the U.S.) from September 2006 to March 2007. Ethical approval from Institutional Review Board and consents from the participants have been collected. Forty-two out of 150 invited schools have participated (see small dots in Figure 1), representing all local non-international secondary schools stratified by district, source of funding, religion, language of instruction, and sex types. All students in the selected schools were invited and 34,678 questionnaires were collected (84.5\% response rate). A total of 9,881 subjects meeting the selection criteria below and with non-missing information of covariates were included in the present analyses.

\section{Data selection}

In Hong Kong, secondary school students spent approximately $80 \%$ of their time at their living and school area altogether (assuming 8 hours per day spent at school for 5 days, 14 hours per day spent at home for 7 days). Their exposures to ambient particulate air pollutant, $\mathrm{PM}_{10}$, were determined by the ambient $\mathrm{PM}_{10}$ levels at both of these locations. As we did not collect the residential addresses of the students, we selected students who were living within twenty-minute walking distance from the school and used the estimates at the school to represent a subgroup that has homogeneity in ambient $\mathrm{PM}_{10}$ exposures in both residential and schooling area. The sample size reduced by $66 \%$ because of this selection and further reduced by $22 \%$ due to missing data of covariates and the health outcome variable of respiratory symptom (details in the following paragraph). Sensitivity analysis on the same health outcome variable was carried out using average $\mathrm{PM}_{10}$ level of the whole Hong Kong area regardless of their residential location (Appendix 1).

\section{Measurement of exposures to $\mathrm{PM}_{10}$ in the past 30 days}

Based on NASA's satellite information, spatial variation of surface extinction coefficients (SEC) with control of cloudiness (99\% cloud free) in each month is mapped at $1-\mathrm{km}^{2}$ resolution in Hong Kong (Li et al 2005). School addresses were geo-coded into geographic coordinates to retrieve this satellite information at each school location. Daily $\mathrm{PM}_{10}$ was estimated by using the daily data from the monitor stations of Environmental Protection Department (EPD) together with the satellite information that addressed the spatial variations. In total 9general stations were used (HKEPD 2008), but 3 roadside stations and 2 other general stations (in Tung Chung and Tap Mun where schools were not sampled) were not used (Figure 1). We calculated the ratios of SEC at each school to mean SEC of all EPD stations. Then we estimated the daily $\mathrm{PM}_{10}$ levels for each school by the product of this ratio and the mean daily $\mathrm{PM}_{10}$ concentration of all stations.

After obtaining the daily $\mathrm{PM}_{10}$ levels for each school, the average $\mathrm{PM}_{10}$ concentration in the past 30 days from the participation date of each student was calculated to represent their average exposures in the past 30 days. This average exposure estimate corresponded to the self-reported respiratory symptoms that could be occurred in any one days over the past 30 days. It should be regarded as a one-month average exposure rather than a short-term exposure, which is usually measured as daily average in time-series epidemiological studies (Wong et al 2001, 2002, 2008; Hedley et al 2002; Wong et al 2006; Ko et al 2007).

\section{Measurement of respiratory symptoms in the past 30 days}

The presence of respiratory symptoms of having frequent cough or sputum in the past 30 days was self-reported by each student in the standardized structured questionnaire. However this health outcome variable showed significant association with the well-known predictor, smoking (Lam et al 1998; Lai et al 2009), after adjustments of appropriate covariates, and is therefore likely a valid measure for respiratory health of children Other illnesses in the past 30 days, such as influenza, sore throat, headache, pimples, musculoskeletal pain, stomachache, and frequent fatigue were also reported if encountered in the past 30 days, and these were used for testing of specificity of the effects of air pollution, as we expected no association.

\section{Data analysis}

The relationship between the student's average exposures to $\mathrm{PM}_{10}$ in the past 30 days as a continuous independent variable and the presence of respiratory symptoms in the past 30 days as a binary dependent variable were assessed by logistic regression based on generalized estimating equation. Within-cluster correlation at school-grade level was controlled for in the analysis. In the regression model adjustments were made for all available potential confounding factors including sex, age, season (excluded summer when no survey was done), student's smoking status, parent's smoking status, average influenza intensity ${ }^{*}$, average temperature in the past 30 days, average relative humidity in the past 30 days, school grade, home floor area, housing type, frequency of exercising for $\geqq 30$ minutes, alcohol drinking status, asthmatic status of the students and their close family members. All statistical analyses are assumed significant at 0.05 level. Data were analyzed using SAS for windows (version 9.1, SAS Institute Inc.).

\section{Results}

The correlation between $\mathrm{PM}_{10}$ levels recorded by the monitoring stations and the satellite information was close to 0.9 both temporally (Figure 2) and spatially (Figure 3). Correlation (R) between the $\mathrm{PM}_{10}$ exposure estimate with and without satellite data was $0.95(\mathrm{P}<0.01)$. Table 1 shows that having respiratory symptoms (cough or sputum) was

\footnotetext{
* based on general practitioner surveillance data from Department of Health in the past 30 days
} 
associated with being female, aged above 15, being Form 4 (equivalent to U.S. grade 9) or above, lived in aided ownership estate, exercising less than once per week, alcohol consumption, having asthma, and having asthmatics among close family members. Lower temperature $(\mathrm{P}<0.01)$ and relative humidity $(\mathrm{P}<0.01)$ were also significantly associated with having respiratory symptoms but the differences between the two comparing groups were small. Sensitivity analysis showed that the results in Table 1 were very similar to the results obtained using the whole group.

Table 2 shows that the excess risk $[95 \% \mathrm{CI}]$ of having respiratory symptoms in the past 30 days was elevated by $4.7 \%$ [0.5\% to $9.1 \%$ ] per $10 \mu \mathrm{g} \mathrm{m}^{-3}$ increase in $\mathrm{PM}_{10}$ concentration. This excess risk was more or less the same among the non-smoking subgroup (4.6\% [0.2\% to 9.2\%]) and the subgroup without asthma (4.7\% [0.1\% to 9.4\%]). The excess risks for female and male subgroups were similar in magnitude but not statistically significant, possibly due to reduction in sample size (females $3.9 \%$ [-1.5\% to $9.4 \%]$ and males $4.8 \%$ [-0.6\% to $10.1 \%]$ ). The excess risks of the rest of the symptoms, including influenza, sore throat, headache, pimples, musculoskeletal pains, stomachache, and frequent fatigue were not associated with increase in $\mathrm{PM}_{10}$ concentrations.

\section{Discussions}

This study shows the health effects of school students' exposures to particulate air pollution at individual locations in Hong Kong. Temporal and spatial variations of air pollution level are used for the assessment. Although the spatial variations were limited to the locations of 42 schools, our sensitivity analysis showed that when only temporal variations were used, the effect of air pollution on respiratory symptoms was attenuated (excess risk from $4.7 \%$ to $3.8 \%$ ) and non-significant (Appendix 1), indicating that the spatial variations were not trivial despite of the modest numbers of geographical locations. This is consistent with the hypothesis that air pollution exposure without taking geographical variation into account is subject to measurement errors (Wade et al 2006). We demonstrated that these measurements from the satellite are in good agreements $(\mathrm{R}=0.9)$, temporally and spatially, with the direct measurements from the ground-level air pollutant monitoring stations during the study period (Figure 2 and Figure 3). Although collection of exposure data at individual locations would help further validate the estimation for exposure level based on satellite data, the large sample size of the present population study would compensate for the uncertainty and errors of measurement at individual level, particularly when estimating the population average health effect rather than the subject specific effect. We also checked that the adjusted associations between respiratory symptoms and smoking were significant and therefore consistent with previous findings (Lam et al 1998), indicating that the observed effects using these measurements of respiratory symptoms is coherent with those using other measurements as health outcome, suggesting that the results derived from this study are valid.

The present study shows that among all reported common symptoms, the association of respiratory symptoms (cough or sputum) with short-term 30-day exposures to particulate air pollution is quite specific. The health effect of about $5 \%$ per $10 \mu \mathrm{g} \mathrm{m}^{-3}$ increase in $\mathrm{PM}_{10}$ is reasonable as the assessment period for the presence of health outcome is long (past 30 days) and the cough or sputum symptoms are very common (21\% prevalence). This association is well supported in the literature (Goren et al 1990; Schwartz et al 1991; Ong et al 1991; Pope and Dockery 1992; Schwartz et al 1994; Peters et al 1996; BraunFahrlander et al 1997; Milligan et al 1998; Qian et al 2000; Zhang et al 2002; BayerOglesby et al 2005).

The crude odds of having influenza, which is also associated with presence of respiratory symptoms, appeared to be elevated by the particulate air pollution, however, the association was no longer observed after regression adjustments. Other symptoms including sore throat, headache, pimples, low back pain, neck pain, stomach pain, and frequent fatigue were clearly not associated with particulate air pollution.

Sensitivity analyses on subgroups showed similar adjusted odds ratios after excluding students who were smokers or who had asthma. Sensitivity analyses by other subgroup stratifications (results not shown), such as close family members without asthmatic history, lower Forms (equivalent to U.S. grade 8 or below) of students, also showed significant air-pollution effects (5\% increased odds) on respiratory symptoms only but not on all the other symptoms. All of these sensitivity analyses further strengthened the validity of our findings and hence the chance of errors due to multiple comparisons (Savitz and Olshan 1995) could be further reduced.

Our results were unlikely to be confounded by seasonality and meteorological conditions since most of the survey fieldwork (over 90\%) was done at the early first semester (September to October) to minimize disturbances on teaching and to avoid the examination periods. Temperature, humidity, and all other unmeasured weather conditions and seasonality were similar during this period. Nevertheless, a disadvantage of this homogeneity within season is a trade off in generalizability of the results to other seasons; and hence, caution is needed when interpreting the results. However, air pollution levels in September and October are usually at the average of the year so that over- or underestimation on health effects of air pollution is unlikely.

When air pollution monitoring data are available nearby these places, temporal variations can also be additionally taken into account. When air pollution monitoring data are not available, the less-revolutionized daily extinction coefficient data can also be used. Nevertheless, the methods in this study can also be used to study the effects of air pollution on other morbidity and mortality outcomes. However, this application of satellite data derived at $1-\mathrm{km}^{2}$ resolution is still limited to studies on particulate air pollution but not yet on other gaseous air pollutants. Besides, the quality of the satellite retrievals is still a major problem to be addressed for exposure and epidemiological researches as when there is still uncertainty in the modeling of tropospheric aerosol retrieval data (Veefkind et al 2007). Nevertheless, improvements can be made by a better characterization of surface and cloud properties, and retrieval 
modeling improvements (Veefkind et al 2007). Existing frameworks for health risk assessment could also benefit from the use of satellite data.

\section{Conclusions}

Health effects due to exposures to particulate air pollution estimated by application of satellite remote sensing information can be assessed. The methods of using satellite data involve very little additional cost for measuring air pollution. Provided the technical uncertainties and limitations of satellite information can be overcome, they can be very useful in places where ground-based ambient air quality monitoring is inadequate, particularly in developing countries, or rural or smaller towns.

\section{References}

Bayer-Oglesby L, Grize L, Gassner M, Takken-Sahli K, Sennhauser FH, Neu U, Schindler C, Braun-Fahrlander C. Decline of ambient air pollution levels and improved respiratory health in Swiss children. Environmental Health Perspectives, 2005; 113: $1632-1637$.

Braun-Fahrlander C, Vuille JC, Sennhauser FH, Neu U, Kunzle T, Grize L, Gassner M, Minder C, Schindler C, Varonier HS, Wüthrich B. Respiratory health and long-term exposure to air pollutants in Swiss schoolchildren. American Journal of Respiratory and Critical Care Medicine, 1997; 155: 1042-1049.

Chu DA, Kaufman YJ, Ichoku C, Remer LA, Tanre D, Holben BN. Validation of MODIS aerosol optical depth retrieval over land. Geophysical Research Letters, 2002; 29: no.12.

Chu DA, Kaufman YJ, Zibordi G, Chern JD, Mao J, Li C, Holben BN. Global monitoring of air pollution over land from the Earth observing System-Terra Moderate Resolution Imaging Spectroradiometer (MODIS). Journal of Geophysical Research, 2003 ; 108 : D21.

Goren AI, Hellman S, Brenner S, Egoz N, Rishpon S. Prevalence of respiratory conditions among schoolchildren exposed to different levels or airpollutants in the Haifa Bay area, Israel. Environmental Health Perspectives, 1990; 89: 225-231.

Gupta P, Christopher SA, Wang J, Gehrig R, Lee Y, Kumar N. Satellite remote sensing of particulate matter and air quality assessment over global cities. Atmospheric Environment, 2006; 40: 5880-5892.

Hedley AJ, Wong CM, Thach TQ, Ma S, Lam TH, Anderson HR. Cardiorespiratory and all-cause mortality after restrictions on sulphur content of fuel in Hong Kong: an intervention study. Lancet. 2002; 360: 1646-1652.

HKEPD. Past Air Quality Monitoring Data. Environmental Protection Department, HKSAR. 2008. Available http://epic.epd.gov.hk/ca/uid/airdata/p/1 [accessed 01 June 2008]

Kaufman YJ, Tanré D, Gordon HR, Nakajima T, Lenoble J, Frouin R, Grassl H, Herman BM, King MD, Teillet PM. Passive remote sensing of tropospheric aerosol and atmospheric correction for the aerosol effect. Journal of Geophysical Research - Atmospheres, 1997; 102: 1681516830 .

Ko FWS, Tam W, Wong TW, Lai CKW, Wong GWK, Leung TF, Ng SSS, Hui DSC. Effects of air pollution on asthma hospitalization rates in different age groups in Hong Kong. Clinical and Experimental Allergy. 2007;37:1312-1319.

Lai HK, Ho SY, Wang MP, Lam TH. Secondhand smoke and respiratory symptoms among adolescent current smokers. Pediatrics, 2009 (in-press).

Lam TH, Chung SF, Betson CL, Wong CM, Hedley AJ. Respiratory symptoms due to active and passive smoking in junior secondary school students in Hong Kong. International Journal of Epidemiology, 1998; 27: 41-8.

Li C, Lau AKH, Mao J, Chu DA. Retrieval, validation, and application of the 1-km aerosol optical depth from MODIS measurements over Hong Kong. IEEE Transactions on Geoscience and Remote Sensing, 2005; 43: 2650-2658.

Milligan PJM, Brabin BJ, Kelly YJ, Pearson MG, Mahoney G, Dunne E, Heaf D, Reid J. Association of spatial distribution of childhood respiratory morbidity with environmental dust pollution. Journal of Toxicology and Environmental Health - Part A, 1998; 55: 169-184.

Monto AS, Cavallaro JJ, Monto AS, Cavallaro JJ. The Tecumseh study of respiratory illness. II. Patterns of occurrence of infection with respiratory pathogens, 1965-1969. American Journal of Epidemiology, 1971; 94: 280-289.

Ong SG, Liu J, Wong CM, Lam TH, Tam AYC, Daniel L, Hedley AJ. Studies on the respiratory health of primary-school children in urban communities of Hong-Kong. Science of the Total Environment, 1991; 106: 121-135.

Peters J, Hedley AJ, Wong CM, Lam TH, Ong SG, Liu J, et al. Effects of an ambient air pollution intervention and environmental tobacco smoke on children's respiratory health in Hong Kong. International Journal of Epidemiology, 1996; 25: 821-828.

Pope CA, Dockery DW. Acute heatlh-effects of PM10 pollution on symptomatic and asymptomatic children. American Review of Respiratory Disease, 1992; 145: 1123-1128.

Qian ZM, Chapman RS, Tian QX, Chen Y, Lioy PJ, Zhang JF. Effects of air pollution on children's respiratory health in three Chinese cities. Archives of Environmental Health, 2000; 55: 126-133.

Remer LA, Kaufman YJ, Tanre D, Mattoo S, Chu DA, Martins JV, Li RR, Ichoku C, Levy RC, Kleidman RG, Eck TF, Vermote E, Holben BN. The MODIS aerosol algorithm, products and validation. Journal of Atmospheric Sciences, 2005; 62: 947-973.

Savitz DA, Olshan AF. Multiple comparisons and related issues in the interpretation of epidemiologic data. American Journal of Epidemiology, 1995; 142: 904-908.

Schwartz J, Dockery DW, Neas LM, Wypij D, Ware JH, Spengler JD, Koutrakis P, Speizer FE, Ferris BG. Acute effects of summer air-pollution on respiratory symptom reporting in children. American Journal of Respiratory and Critical Care Medicine, 1994; 150: 1234-1242.

Schwartz J, Wypij D, Dockery D, Ware J, Zeger S, Spengler J, Ferris B. Daily diaries of respiratory symptoms and air-pollution - Methodological issues and results. Environmental Health Perspectives, 1991; 90: 181-187.

Veefkind P, van Oss RF, Eskes H, Borowiak A, Dentner F, Wilson J. The applicability of remote sensing in the field of air pollution. European Commission, Directorate-General Joint Research Centre, Institue for Environment and Sustainability, 2007; EUR22542EN.

Wade KS, Mulholland JA, Marmur A, Russel AG. Effects of instrument precision and spatial variability on the assessment of the temporal variation of ambient air pollution in Atlanta, Georgia. Journal of Air and Waste Management Association, 2006; 56: 879-888.

Wang J, Christopher SA. Intercomparison between satellite-derived aerosol optical thickness and PM2.5 mass: implications for air quality studies. Geophysical Research Letters, 2003; 30: 2095.

Wong CM, Atkinson RW, Anderson HR, Hedley AJ, Ma SLS, Chau YK, Lam TH. A tale of two cities: effects of air pollution on hospital admissions in Hong Kong and London compared, Environmental Health Perspectives, 2002; 110: 67-77.

Wong CM, Ma SLS, Hedley AJ, Lam TH. Effect of air pollution on daily mortality in Hong Kong, Environmental Health Perspectives, 2001; 109: 335-340.

Wong CM, Vichit-Vadakan N, Kan H, Qian Z. Public Health and Air Pollution in Asia (PAPA): a multicity study of short-term effects of air pollution on mortality. Environ Health Perspect. 2008; 116: 1195-202.

Wong TW, Tam W, Yu ITS, Wun YT, Wong AHS, Wong CM. The association between air pollution and general practitioner visits for respiratory diseases in Hong Kong. Thorax. 2006; 61: 585-591.

Zhang JF, Hu W, Wei FS, Wu GP, Korn LR, Chapman RS. Children's respiratory morbidity prevalence in relation to air pollution in four Chinese cities. Environmental Health Perspectives, 2002; 110: 961-967. 
Table 1. Descriptive statistics (column \% or group mean with $95 \%$ CI) for students having or not having respiratory symptoms (cough or sputum).

\begin{tabular}{|c|c|c|c|c|}
\hline \multicolumn{2}{|c|}{ Presence of respiratory symptoms (cough or sputum) } & \multirow{2}{*}{ 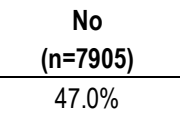 } & \multirow{2}{*}{$\begin{array}{c}\begin{array}{c}\text { Yes } \\
(n=1976)\end{array} \\
35.3 \%\end{array}$} & \multirow{2}{*}{$\frac{\text { p-value }}{0.000}$} \\
\hline Sex & Male & & & \\
\hline & Female & $53.0 \%$ & $64.7 \%$ & \\
\hline \multirow[t]{2}{*}{ Age group } & 15 or below & $64.8 \%$ & $60.2 \%$ & 0.000 \\
\hline & Above 15 & $35.2 \%$ & $39.8 \%$ & \\
\hline Student's smoking & Never or ex-smokers & $97.0 \%$ & $96.3 \%$ & 0.081 \\
\hline \multirow[t]{2}{*}{ status } & Occasional smokers & $1.6 \%$ & $1.6 \%$ & \\
\hline & Active smokers ( $\geq 1$ cig./week) & $1.5 \%$ & $2.2 \%$ & \\
\hline \multirow[t]{2}{*}{ Parent's smoking status } & Both never smoke & $55.6 \%$ & $53.9 \%$ & 0.190 \\
\hline & Either or both smoke & $44.4 \%$ & $46.1 \%$ & \\
\hline \multirow[t]{4}{*}{ School grade } & Form 1 & $18.3 \%$ & $17.9 \%$ & 0.000 \\
\hline & Form 2-3 & $39.5 \%$ & $32.1 \%$ & \\
\hline & Form 4-5 & $32.7 \%$ & $38.0 \%$ & \\
\hline & Form 6-7 & $9.4 \%$ & $11.9 \%$ & \\
\hline Residential area (square & 199 or less & $3.3 \%$ & $2.8 \%$ & 0.091 \\
\hline \multirow[t]{4}{*}{ feet) } & $200-399$ & $16.6 \%$ & $16.4 \%$ & \\
\hline & $400-799$ & $60.0 \%$ & $62.8 \%$ & \\
\hline & $800-999$ & $12.0 \%$ & $11.3 \%$ & \\
\hline & 1000 or above & $8.1 \%$ & $6.7 \%$ & \\
\hline \multirow[t]{5}{*}{ Housing type } & Public housing estate & $47.8 \%$ & $47.0 \%$ & 0.013 \\
\hline & Aided ownership estate & $12.4 \%$ & $15.1 \%$ & \\
\hline & Private housing & $37.3 \%$ & $36.0 \%$ & \\
\hline & Temporary housing & $0.5 \%$ & $0.4 \%$ & \\
\hline & Others or quarters & $2.0 \%$ & $1.5 \%$ & \\
\hline Frequency of exercising & None & $22.5 \%$ & $24.5 \%$ & 0.000 \\
\hline \multirow[t]{3}{*}{ for 30 minutes or more } & Less than once per week & $28.3 \%$ & $31.2 \%$ & \\
\hline & 1-3 times per week & $31.8 \%$ & $30.1 \%$ & \\
\hline & 4 times or more per week & $17.5 \%$ & $14.2 \%$ & \\
\hline Drank any alcohol in the & Yes & $16.2 \%$ & $18.2 \%$ & 0.040 \\
\hline past 30 days & None & $83.8 \%$ & $81.8 \%$ & \\
\hline Physician-diagnosed & No & $94.8 \%$ & $92.4 \%$ & 0.000 \\
\hline asthma & Yes & $5.2 \%$ & $7.6 \%$ & \\
\hline Any asthmatics among & No & $94.0 \%$ & $89.5 \%$ & 0.000 \\
\hline close family members & Yes & $6.0 \%$ & $10.5 \%$ & \\
\hline \multirow[t]{3}{*}{ Season } & Spring (Mar) & $2.7 \%$ & $2.2 \%$ & 0.453 \\
\hline & Autumn (Sept to Oct) & $90.0 \%$ & $90.8 \%$ & \\
\hline & Winter (Nov to Dec) & $7.3 \%$ & $6.9 \%$ & \\
\hline $\begin{array}{l}\text { Rate of influenza-like } \\
\text { illness* }\end{array}$ & & $39.7(2.8,39.8)$ & $39.8(2.6,39.9)$ & 0.172 \\
\hline Temperature $\left({ }^{\circ} \mathrm{C}\right)$ & & $27.4(1.6,27.4)$ & $27.2(1.5,27.3)$ & 0.001 \\
\hline Relative humidity (\%) & & $80.6(2.7,80.7)$ & $80.4(2.7,80.5)$ & 0.000 \\
\hline
\end{tabular}

Table 2. Odds ratios (95\% CI) of having symptom as compared to not having symptom in the past 30 days associated with $10 \mu \mathrm{g} \mathrm{m}^{-3}$ increase in $\mathbf{P M}_{10}$ using all valid samples and the subgroups of non-smokers and individuals without asthma.

\begin{tabular}{|c|c|c|c|c|c|c|}
\hline \multirow[b]{2}{*}{ Outcomes } & \multirow[b]{2}{*}{$n_{0}$} & \multirow[b]{2}{*}{$\mathrm{n}_{1}$} & \multicolumn{2}{|l|}{ All $(n=9881)$} & \multirow{2}{*}{$\begin{array}{l}\text { Non-smokers } \\
(\mathrm{n}=9145) \\
\text { Adjusted odds ratios }\end{array}$} & \multirow{2}{*}{$\begin{array}{l}\text { Individuals without } \\
\text { asthma ( } n=9316) \\
\text { Adjusted odds ratios }\end{array}$} \\
\hline & & & Crude odds ratios & Adjusted odds ratios & & \\
\hline Cough or sputum & 7905 & 1976 & $1.042(0.998,1.088)$ & $1.047(1.005,1.091)^{*}$ & $1.046(1.002,1.092)^{*}$ & $1.047(1.001,1.094)^{*}$ \\
\hline Influenza & 8406 & 1475 & $1.088(1.041,1.137)^{\star * *}$ & $1.029(0.985,1.076)$ & $1.028(0.982,1.076)$ & $1.024(0.976,1.074)$ \\
\hline Sore throat & 7732 & 2149 & $1.047(1.001,1.096)^{\star}$ & $1.026(0.987,1.066)$ & $1.027(0.990,1.065)$ & $1.026(0.980,1.074)$ \\
\hline Headache & 7989 & 1892 & $1.010(0.944,1.080)$ & $1.015(0.972,1.061)$ & $1.019(0.973,1.068)$ & $1.017(0.970,1.066)$ \\
\hline Pimples & 6711 & 3170 & $0.987(0.933,1.044)$ & $1.011(0.975,1.049)$ & $1.016(0.979,1.056)$ & $1.009(0.972,1.048)$ \\
\hline Low back pain & 8930 & 951 & $0.978(0.906,1.056)$ & $1.009(0.950,1.072)$ & $0.998(0.935,1.066)$ & $1.009(0.948,1.074)$ \\
\hline Neck pain & 9122 & 759 & $1.033(0.969,1.101)$ & $1.009(0.952,1.069)$ & $1.007(0.946,1.072)$ & $1.009(0.953,1.069)$ \\
\hline Stomach ache & 9073 & 808 & $0.948(0.881,1.021)$ & $0.988(0.919,1.063)$ & $0.988(0.913,1.070)$ & $1.005(0.938,1.078)$ \\
\hline Frequent fatigue & 7996 & 1885 & $1.037(0.974,1.103)$ & $1.015(0.967,1.065)$ & $1.013(0.964,1.065)$ & $1.016(0.966,1.070)$ \\
\hline
\end{tabular}


Figure 1. Locations of the air quality monitoring stations and schools in Hong Kong

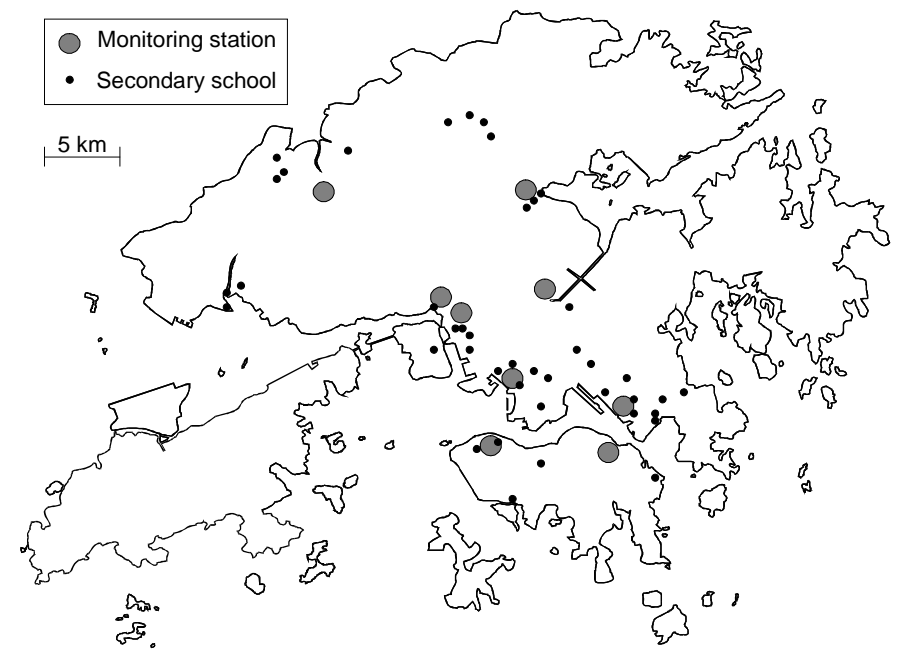

Figure 2. Temporal linear association $(\mathbf{p}<0.01)$ between $P M_{10}$ concentration measured by ground monitoring stations and surface extinction coefficients detected by the satellite from January 2006 to December 2007.

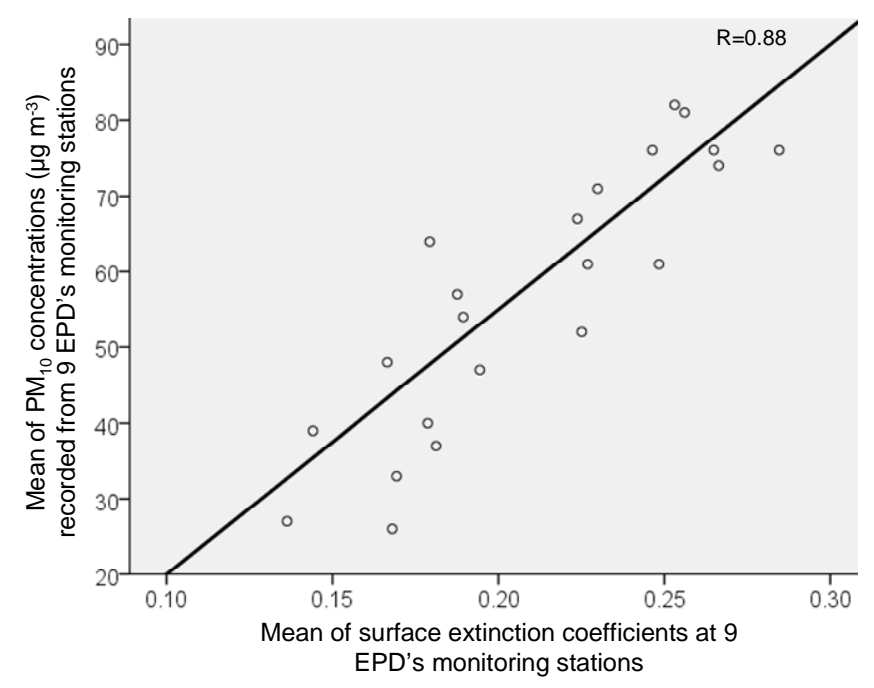

Figure 3. Spatial linear association $(\mathbf{p}<0.01)$ between annual mean $\mathbf{P M}_{10}$ concentration measured at each ground monitoring station and the annual mean surface extinction coefficients detected by the satellite in year 2006.

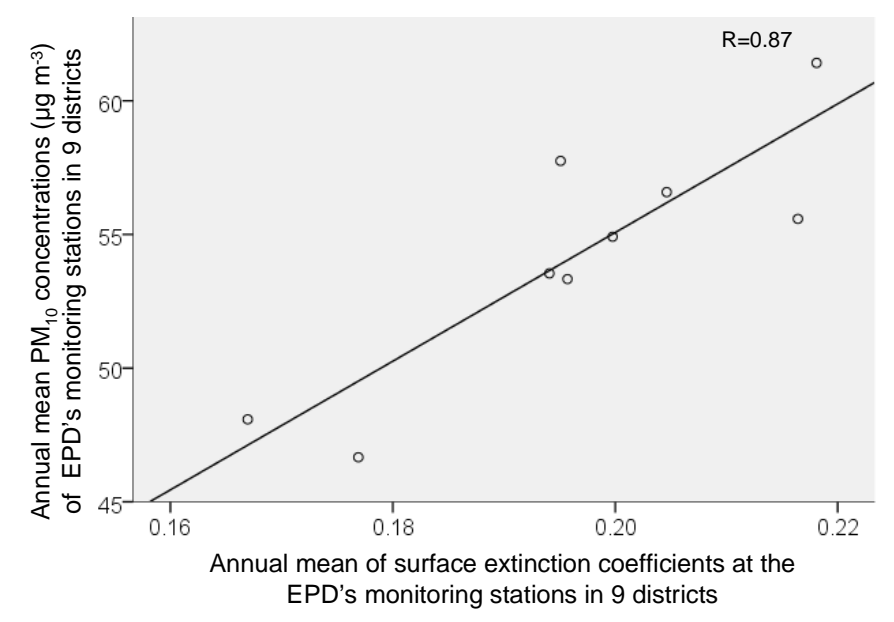

'EPD' refers to Environmental Protection Department in Hong Kong. 


\section{Appendix 1}

Sensitivity analysis on the same selected group ( $\mathrm{n}=9881)$ using the mean $\mathrm{PM}_{10}$ level recorded by EPD monitoring stations regardless of the spatial variations: Odds ratios (95\% CI) of having symptom as compared to not having symptom in the past 30 days associated with $10 \mu \mathrm{g} \mathrm{m}^{-3}$ increase in $\mathrm{PM}_{10}$.

\begin{tabular}{|l|llll|}
\hline Outcomes & $\mathrm{n}_{\mathbf{0}}$ & $\mathrm{n}_{1}$ & Crude odds ratios & Adjusted odds ratios \\
\hline Cough or sputum & 7905 & 1976 & $1.040(0.994,1.087)$ & $1.038(0.995,1.083)$ \\
Influenza & 8406 & 1475 & $1.091(1.041,1.143)^{\star * *}$ & $1.028(0.981,1.077)$ \\
Sore throat & 7732 & 2149 & $1.048(0.999,1.100)$ & $1.019(0.978,1.062)$ \\
Headache & 7989 & 1892 & $1.006(0.938,1.079)$ & $1.015(0.967,1.065)$ \\
Pimples & 6711 & 3170 & $0.984(0.926,1.044)$ & $1.006(0.967,1.047)$ \\
Low back pain & 8930 & 951 & $0.983(0.909,1.063)$ & $1.018(0.957,1.083)$ \\
Neck pain & 9122 & 759 & $1.032(0.965,1.104)$ & $1.006(0.946,1.070)$ \\
Stomach ache & 9073 & 808 & $0.952(0.879,1.030)$ & $0.995(0.922,1.074)$ \\
Frequent fatigue & 7996 & 1885 & $1.039(0.973,1.109)$ & $1.015(0.967,1.066)$ \\
\hline $\begin{array}{l}{ }^{*} p<0.05, \text { *** } p<0.001 . \\
\text { cluster correlations by school-grade level were used. All adjusted odds ratios were obtained with adjustments for }\end{array}$ \\
$\begin{array}{l}\text { sex, age, season, influenza intensity, temperature, relative humidity, student's smoking status, parent's smoking } \\
\text { status, school grade, home floor area, housing type, exercise frequency, alcohol drinking status, student's asthmatic } \\
\text { status, student's close family members' asthmatic status, whenever these covariates were available in the analyses. }\end{array}$ \\
\hline
\end{tabular}

\section{Appendix 2 - All other symptoms not presented in the main results (for conciseness)}

Odds ratios (95\% CI) of having symptom as compared to not having symptom in the past 30 days associated with $10 \mu \mathrm{g}$ $\mathrm{m}^{-3}$ increase in $\mathrm{PM}_{10}$ using all valid samples and the subgroups of non-smokers and individuals without asthma.

\begin{tabular}{|c|c|c|c|c|c|c|}
\hline \multirow[b]{2}{*}{ Outcomes } & \multirow[b]{2}{*}{$n_{0}$} & \multirow[b]{2}{*}{$\mathrm{n}_{1}$} & \multicolumn{2}{|l|}{ All (n=9881) } & \multirow{2}{*}{ 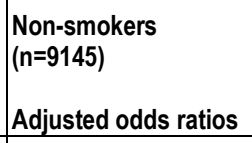 } & \multirow{2}{*}{$\begin{array}{l}\text { Individuals without } \\
\text { asthma }(n=9316) \\
\text { Adjusted odds ratios }\end{array}$} \\
\hline & & & Crude odds ratios & Adjusted odds ratios & & \\
\hline Dizziness & 8478 & 1403 & $1.001(0.947,1.059)$ & $1.006(0.962,1.051)$ & $1.003(0.954,1.054)$ & $1.007(0.964,1.052)$ \\
\hline Bad breath & 9401 & 480 & $1.022(0.945,1.106)$ & $1.010(0.936,1.090)$ & $0.997(0.912,1.091)$ & $1.011(0.932,1.098)$ \\
\hline Fainting & 9789 & 92 & $1.077(0.902,1.286)$ & $1.046(0.878,1.245)$ & $1.038(0.854,1.261)$ & $1.082(0.904,1.296)$ \\
\hline Upper limbs pain & 9599 & 282 & $0.963(0.860,1.079)$ & $0.996(0.893,1.111)$ & $0.990(0.891,1.100)$ & $1.008(0.914,1.113)$ \\
\hline Lower limbs pain & 9486 & 395 & $1.024(0.933,1.124)$ & $1.017(0.926,1.117)$ & $1.024(0.930,1.128)$ & $1.045(0.949,1.151)$ \\
\hline Abdominal pain & 8668 & 1213 & $1.002(0.945,1.063)$ & $1.001(0.942,1.063)$ & $1.005(0.943,1.071)$ & $0.995(0.937,1.057)$ \\
\hline Bloating & 9525 & 356 & $0.899(0.807,1.002)$ & $0.924(0.832,1.026)$ & $0.931(0.832,1.041)$ & $0.943(0.859,1.035)$ \\
\hline Constipation & 9443 & 438 & $0.960(0.863,1.068)$ & $0.985(0.888,1.093)$ & $0.987(0.883,1.103)$ & $1.001(0.909,1.104)$ \\
\hline Diarrhea & 9320 & 561 & $0.934(0.854,1.021)$ & $0.971(0.892,1.057)$ & $0.963(0.879,1.055)$ & $0.973(0.896,1.057)$ \\
\hline Vomiting & 9657 & 224 & $0.860(0.746,0.990)^{*}$ & $0.911(0.789,1.052)$ & $0.900(0.765,1.060)$ & $0.914(0.783,1.067)$ \\
\hline Snoring & 9211 & 670 & $1.014(0.936,1.099)$ & $1.033(0.953,1.119)$ & $1.014(0.930,1.105)$ & $1.046(0.959,1.142)$ \\
\hline Anxiety & 9292 & 589 & $1.003(0.891,1.128)$ & $1.015(0.925,1.114)$ & $1.007(0.906,1.119)$ & $1.018(0.931,1.112)$ \\
\hline Depression & 9524 & 357 & $1.018(0.902,1.148)$ & $1.027(0.918,1.148)$ & $1.032(0.918,1.159)$ & $1.027(0.919,1.149)$ \\
\hline
\end{tabular}

